\title{
International students' perceptions of healthy eating before and after arrival in Canada: A qualitative study.
}

\author{
A. Corkum ${ }^{1}$, K. Gottschall-Pass ${ }^{1}$, S. Hewko ${ }^{1}$, D. MacLellan ${ }^{1}$
}

'Department of Applied Human Sciences, University of Prince Edward Island, PE, Canada.

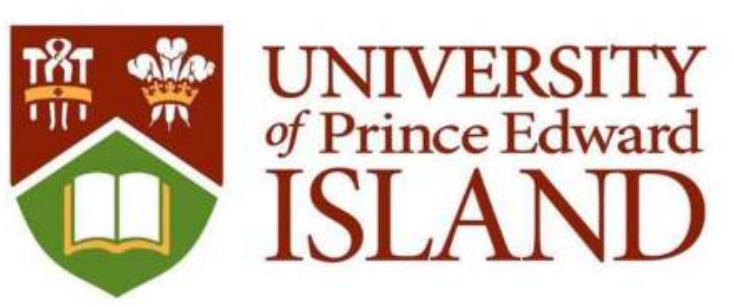

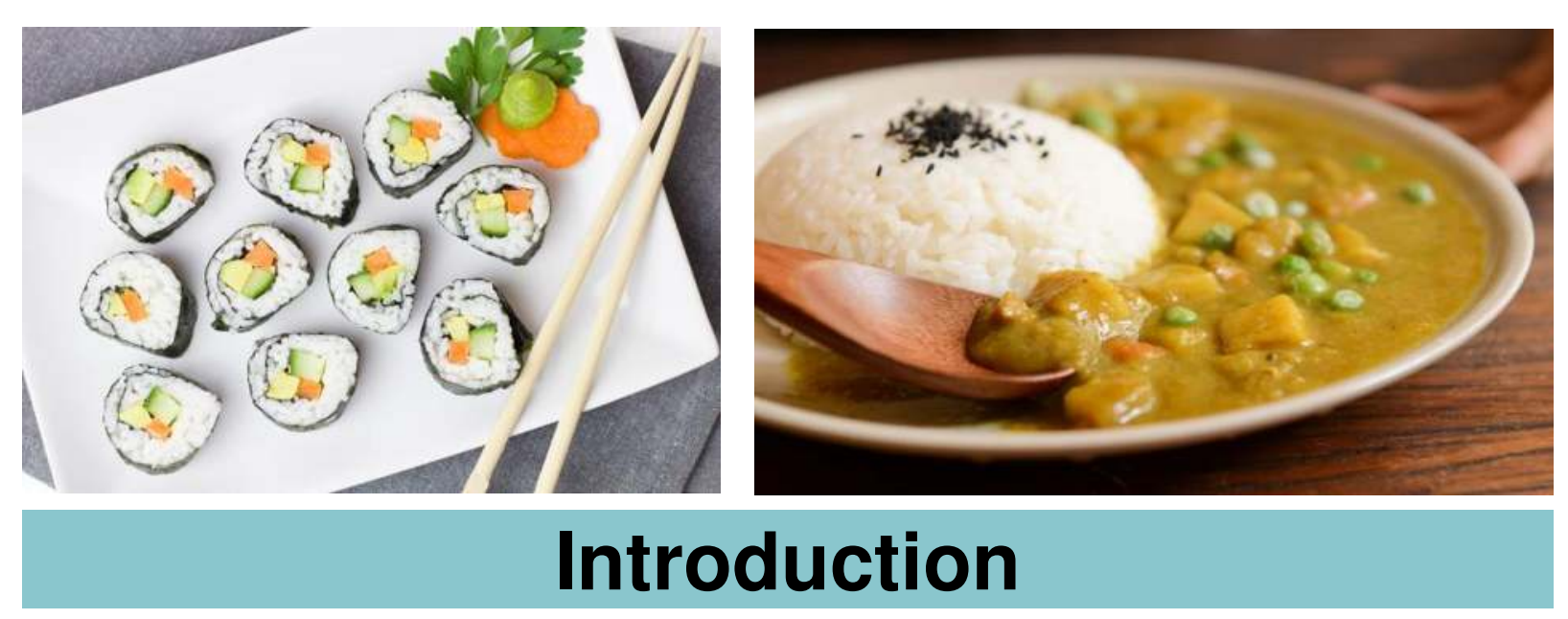

- The campus environment, individual factors, and the food environment influence students' acculturation to Canada (1).

- International students report higher consumption of fat and sugar, large portion sizes, fast food, snacks, and sugarsweetened beverages in Canada than when living in their home country (2).

- Time since arrival in Canada is correlated with higher BMI, increased frequency of health care usage, increased onset of chronic conditions, and a decline in self-assessed health (3).
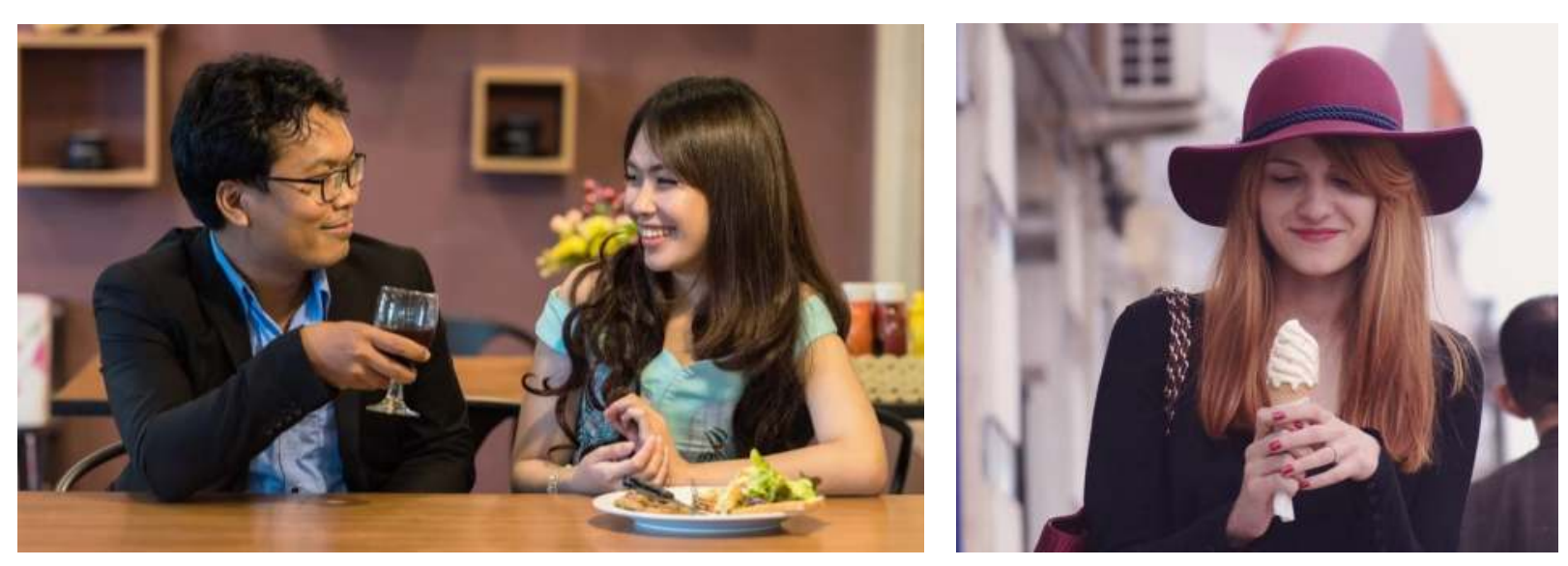

\section{Objectives}

Explore international students':

(1) perceptions of a healthy diet in their country of origin,

(2) perceptions of a healthy diet in Canada, and

(3) how their perception of a healthy diet has changed since their arrival in Canada.

\section{Methods}

A qualitative descriptive design was used where in-depth, oneon-one interviews were conducted with 13 international students at UPEI. The interviews were transcribed from audio recordings and analyzed using thematic analysis.

\section{Table 1: Participants' demographic information}

\begin{tabular}{|c|c|c|c|c|c|}
\hline Age & Sex & $\begin{array}{l}\text { Country of } \\
\text { origin }\end{array}$ & Major & $\begin{array}{l}\text { Nutrition } \\
\text { education } \\
\text { exposure }\end{array}$ & $\begin{array}{l}\text { Year } \\
\text { of } \\
\text { study }\end{array}$ \\
\hline 22 & $\mathrm{M}$ & Hong Kong & Anthropology & No & 4 \\
\hline 20 & $M$ & France & $\begin{array}{l}\text { Environmental } \\
\text { Studies }\end{array}$ & No & 3 \\
\hline 21 & $\mathrm{~F}$ & Japan & Business & No & 3 \\
\hline 20 & $\mathrm{M}$ & Mexico & Engineering & No & 2 \\
\hline 21 & $\mathrm{M}$ & China & Business & No & 4 \\
\hline 22 & $\mathrm{~F}$ & Spain & Journalism & No & 5 \\
\hline 18 & $\mathrm{~F}$ & Vietnam & Kinesiology & No & 1 \\
\hline 21 & $\mathrm{~F}$ & Mauritius & Biology & No & 2 \\
\hline 21 & $\mathrm{~F}$ & China & Nutrition & Yes & 4 \\
\hline 19 & $\mathrm{~F}$ & Sri Lanka & Biology & Yes & 2 \\
\hline 23 & M & Vietnam & Biotechnology & No & 2 \\
\hline 19 & $\mathrm{~F}$ & Syria & Computer Science & No & 2 \\
\hline 21 & M & Nigeria & Nursing & No & 3 \\
\hline
\end{tabular}
1) Alakaam, Castellanos, Bodzio, \& Harrison (2015) Journal of International Students, 104(2), 104-120; 2) Amos \& Lordly (2014)
Canadian Journal of Dietetic Practice and Research, 75(2), 59-63; 3) Sanou et al (2014) J Immigr Minor Heal, 16(1):24-34.

\begin{tabular}{ll}
\multicolumn{1}{c}{ Results } \\
\hline Theme & Illustrative quotes \\
\hline Preference for & "...Um, typical favourite meal would be like \\
Traditional Foods & $\begin{array}{l}\text { rice with some curries, that's it, and that } \\
\text { would include like vegetables and usually } \\
\text { and Meals }\end{array}$
\end{tabular}

Associating

Traditional Foods

with Healthy Eating

"Yeah, and now that I come here, I feel like I usually skip breakfast, and then just eat brunch, and dinner, and eat a lot of snacks...".

The Transition from " "... I don't need to cook by myself because Familial to Individual it's very convenient and cheaper to eat Cooking Practices outside, but here we need to cook by ourselves...".

Reading Labels on 'It's like the market that like we usually go Processed Foods out and get food, it's not-well, I mean I don't go to supermarkets".

Distrust of the Food "Like, I think-I consider canned stuff to be Supply unhealthy food because they last very long time. But instead of lasting long time, the people put a lot of like artificial things in it...".

Discovering Non"But I do have some of like rice, soup, and fish-oh, no, no meat dish still, I still have that as a basic thing and then I do include like western foods, like yogurt. I don't really eat yogurt back in Vietnam".

Traditional Food Availability in "But here, it's like I don't eat fish. I want to, but it's too expensive".

Canada

Reliance on

"I go to fast food, I go to SubWay, yeah. That Convenience Foods would be most of my like going out, I think. And l eat a lot of snacks".

Changing Views of "Because I used to be a lot chubbier, like Healthy Eating chubbiness is healthy for us, and my mom would think that I am like anorexic right now...".

\section{Conclusions}

- This study illuminates international students' perceptions of a healthy diet in their country of origin and in Canada, and how their perceptions may have changed since their arrival in Canada.

- Further research is needed to better understand international students' experiences with food and perceptions of healthy eating.

\section{Implications for Practice}

- International students often prefer traditional foods and perceive them as healthier, which can make assimilating into Canadian culture more difficult.

- Cost and availability are barriers for students to eat healthy traditional meals.

- Programs to help international students find affordable traditional foods and integrate Canadian foods into traditional recipes may help bridge the gap between diet cultures. 